\title{
412 単段・二段カスケード型吸着冷凍サイクル
}

Single - Double combined Adsorption Refrigeration Cycle with Heat Source Cascading System

\begin{tabular}{|c|c|c|c|c|c|}
\hline 0 大内 & 新平 & (東京農工大学) & & K. C. Amanul Alam & (東京農工大学) \\
\hline 正 & 芳徳 & (東京農工大学) & 正 & 秋澤 淳 & (東京農工大学) \\
\hline 柏木 & 孝夫 & (東京農工大学) & & & \\
\hline
\end{tabular}

Shinpei OHUCHI, K. C. Amanul Alam, Yoshinori HAMAMOTO, Atsushi AKISAWA, and Takao KASHIWAGI Tokyo University of Agriculture and Technology, 2-24-16 Nakacho, Koganci, Tokyo

\begin{abstract}
The study aims at investigating the performance of silica gel-water single-double combined adsorption refrigeration cycle. The rejected waste heat from the conventional single-stage adsorption chiller is usually purged to the drain. The heat that rejected from the single stage, however, can be used for regeneration of a two-stage chiller because two-stage chiller can utilize relatively low temperature heat source to drive the system. Single-Double combined adsorption refrigeration cycle can provide higher performance. Due to cascaded use of heat source, the cooling capacity of the proposed cycle is expected to be higher than that of the existing refrigeration cycle. The performanee that predicted by cycle simulation is compared with the performances of conventional single stage and double stage cycles. The results show that the proposed cycle improves cooling capacity significantly in driving source temperature between $65^{\circ} \mathrm{C}$ and $80^{\circ} \mathrm{C}$. Single-Double combined cycle is effective if heat source temperature is middle.
\end{abstract}

Keywords : Adsorption, Silica gel, Single-double combined cycle, Cooling capacity

\section{1. 緒言}

近年のエネルギー需要增大に伴う温室効果ガスの排出を 抑制するために，排熱または再生可能エネルギーにより作 動が可能であるアドバンス卜吸収・吸着冷凍機に関心が示 されている。吸收・吸着サイクルは水やアンモニアなどの 自然椧媒を使用ずるため，これまで主流であった CFCや HCFC 系作動流体を利用した空調システムと比較して環境 への負荷が小さい，また，排熱駆動型であるこれらの冷凍 機法排熱回収・エネルギーのカスケード的利用を考慮した 場合，非常に有効なシステムである。排熱利用においては

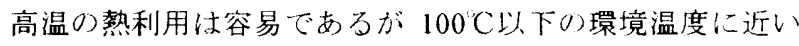
比較的低温度頒域に㧈计乃熱利用は技術的に困難であり， 低温排熱回収技術の確立が重要視されている。

現在，単段型吸着冷凍機が実用化されて㧍り，30 $\mathrm{C}$ 冷 却水に対して 70〜90Cの熱源（温水）での駆動が可能であ $\zeta^{(1)}(3)$. 単段型吸着冾凍機 $の$ )駆動温度限界注吸着剂熱交換 器を三段型と寸ることに上り克服され， $30 \mathrm{C}$ の偷却水に対 して 40〜50只の駆動熱源で駆動が可能であることが確認 されており，低温度域において駆動が可能であることが証 明されている(2).(4).(5)。これらに対し成績係数 (COP) や渝 房能力の向上を目的とし, $30^{\circ} \mathrm{C} の$ 伶却水に対して 50〜70 $\mathrm{C}$ の熱源での駆動が可能である二段型吸着冷凍けイクルが考 案され, 有効性が確認された。

このように吸着冷凍機は低温度域での駆動が可能である ことは証明されてきたが，「低温排熱でも駆動可能」という 同じメリットを持つ吸収泠凍機と比較して性能が低いとい う欠点を持っている。そこで様々な吸着泠凍サイクルの性 能評価を可能と寸る6ベッド多段型吸着洽凍機を迸入して, シミュレーションと実験より吸着泠凍機のさらなる高性能 化のための指針を探っていく. 本研究では単段型サイクル と二段型サイクルの駆動熟源の温度レベルの差に着目し，

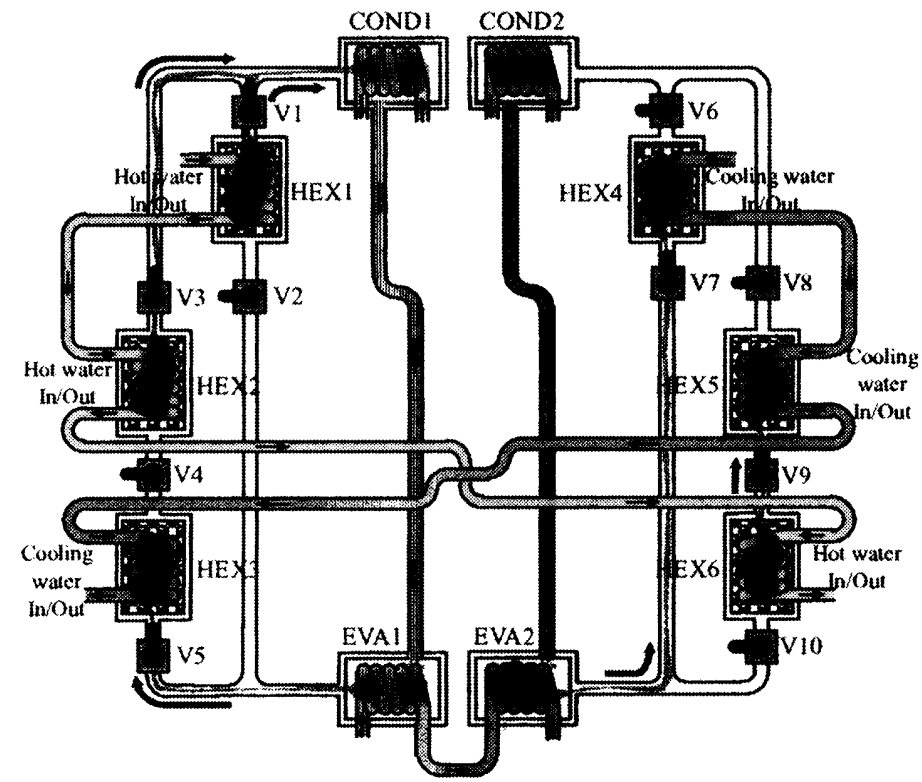

Fig. 1 Schematic of Single-Double combined Cycle.

加熱水をカスケード利用寸ることで佮房能力の搪大を目指 した単段・二段カスケード型サイクルについてシミュレー ションを行い, 従来型サイクルである単段型・二段型と比 較し，その有効性を検証した。

2. 単殷・二段カスケード型吸着冷凍サイクル

吸着泠凍機は吸脱着器, 蒸発器, 凝縮器により構成され, 本研究に执いては吸着剤にシリカダル，吸着質 (以下冷媒)

〔No.03-10〕日本機械学会第 13 回環境工学総合シンポジウム 2003 講演論文集〔2003.6.25〜27·川崎〕 
に水老用いて運転しており，吸着工程，準借加熱工程，脱 着工程, 䒜備冷却工程からなる。吸着工程では蒸発器で蒸 気となった泠媒が圧力差に上り吸脱着器に送られシリカ ゲルに吸着される。このとき伶媒が蒸発器内を流れる冷水 から蒸発潜熟を奪い冾熱を得る。脱着工程では吸脱着器内 を温水で加熱寸ることによって份媒がシりカダル上り脱 着し, 蒸父となって凝縮器に放出され凝縮器内を流孔る泠 却水に上り渝却され液化技方。この凝縮水が压力差に上り 蒸発器に戻され，泠媒が系内を循環する。脱着工程では渝 熱が得られないため2 基の吸脱着器在 1 組のベアよし, 吸・脱着工程を交互に位相差運転寸ることに上り連続的に 椧熱在得る。

6ベッド多段型吸着泠凍機は6基の吸脱着器(3 組のベア) とともに, 2 基の蒸発器, 2 基 0 凝縮器在有寸万. 加熱水, 渝 却水は運転モードに応じてカスケード的に流寸こ上も可能 に設計されている.Fig. 1 に単段・二段カスケード型吸着偷 凍サイクルの概略図を示し，Fig. 2 にデューリング線図を示 寸。本サイクルは上段 1 組の吸脱着器のべアからなる単段 型サイタルと下段 2 組 $の$ 吸脱着器のバアからなる二段型少 イクルを結合したものである。ここで 4 つの工程をそれぞ れ $\mathrm{A}, \mathrm{B}, \mathrm{C}, \mathrm{D}$ とおいて, バルブの開閉扩よび吸脱着器内を 流机万加熱水, 泠却水の選択は Tab.1の夕イムチャートに 従い制御寸る。

\section{3. サイクルシミュレーション}

6 ベッド多段型吸着渝凍機の吸脱着器, 蒸発器, 凝縮器 内に拉りる吸着現象について，エネルギ一収支および物質 収支け基礎方程式を用いてモデル化し，サイクルシミュレ 一ションに上る性能解析老行った。

3.1 吸脱着器におけるエネルギーバランス

吸脱着器におお汁る治却水出口温度，エネルギーバランス は次式で表される。

$T_{o u}=T_{b}+\left(T_{i n}-T_{b}\right) \exp \left(-\frac{U_{b} A_{b}}{\dot{m}_{w} C_{w}}\right)$

$\frac{d}{d t}\left\{\left(W_{s} C_{s}+W_{s} C_{w} q+W_{H t X} C_{t I t X X}\right) T_{h}\right\}=W_{s} Q_{s t} \frac{d q}{d t}$

$-\delta \cdot W_{s} C_{v}\left\{\gamma\left(T_{b}-T_{c}\right) \frac{d q}{d t}+(1-\gamma)\left(T_{b}-T_{v}\right) \frac{d q}{d t}\right\}+\dot{m}_{u} C_{w}\left(T_{i n}-T_{c u t}\right)$

$\delta=0$ or $1:$ Bed is working as a desorber or adsorber $\gamma=1$ or $0:$ Bed is connected with evaporator or another bed

3.2 凝縮器におけるエネルギーバランス

凝縮器にお朾る份却水出口温度, エネルギーバランスは 次式で表される.

$$
T_{c w ; o u t}=T_{c}+\left(T_{c w, i n}-T_{c}\right) \exp \left(-\frac{U_{c} A_{c}}{\dot{m}_{c w} C_{w}}\right)
$$

Tab. I Time chart of the chiller operation.

\begin{tabular}{|c|c|c|c|c|c|}
\hline & Mode & A & B & C & D \\
\hline & Time [s] & 420 & 30 & 420 & 30 \\
\hline \multirow{2}{*}{ Valve } & $1,4,6,8,10$ & 0 & $\times$ & $\times$ & $\times$ \\
\hline & $2,3,5,7,9$ & $x$ & $x$ & $\mathrm{O}$ & $x$ \\
\hline \multirow{2}{*}{ HEX } & $1,2,6$ & $\mathrm{CW}$ & HW & HW & $\mathrm{CW}$ \\
\hline & $3,4,5$ & HW & $\mathrm{CW}$ & $\mathrm{CW}$ & HW \\
\hline & $O:$ Open & \multicolumn{4}{|c|}{ HW : Hot Water } \\
\hline & $\times:$ Close & \multicolumn{4}{|c|}{ CW : Cooling Water } \\
\hline
\end{tabular}

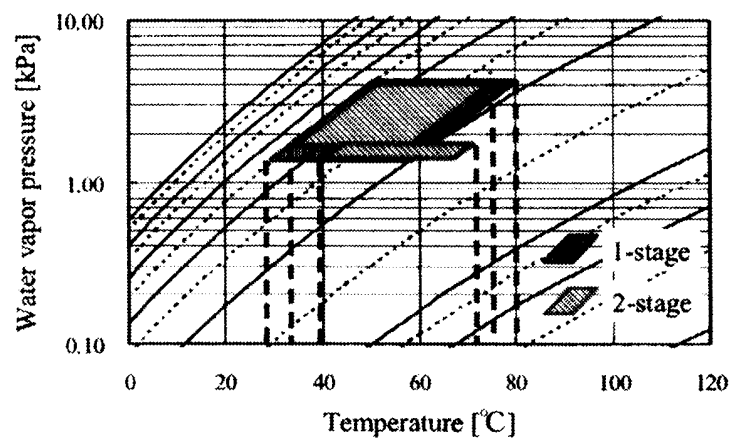

Fig. 2 Conceptual Duhring diagram for Single-Double combined Cycle

$$
\begin{aligned}
& \frac{d}{d t}\left\{\left(W_{c, w} C_{w^{\prime}}+W_{c, H E X} C_{c, H E X}\right) T_{c}\right\}=-L W_{s} \frac{d q_{d e s}}{d t} \\
& -W_{s} C_{v}\left(T_{d e s}-T_{c}\right) \frac{d q_{d e s}}{d t}+\dot{m}_{c w^{\prime}} C_{w^{\prime}}\left(T_{c w . i n}-T_{c w, o u t}\right)
\end{aligned}
$$

\section{3 蒸発器におけるエネルギーバランス}

蒸発器に㧍ける治却水出口温度，エネルギーバランスは 次式で表される。

$T_{\text {chill,out }}=T_{e}+\left(T_{\text {chill,in }}-T_{e}\right) \exp \left(-\frac{U_{e} A_{e}}{\dot{m}_{\text {chill }} C_{\mathrm{u}}}\right)$

$\frac{d}{d t}\left\{\left(W_{e w} C_{w}+W_{e, H E X} C_{e, H E X}\right) T_{e}\right\}=-L W_{s} \frac{d q_{a d s}}{d t}$

$-W_{s} C_{w}\left(T_{c}-T_{e^{\prime}}\right) \frac{d q_{d e s}}{d t}+\dot{m}_{c h i l l} C_{w}\left(T_{c h i l l, i n}-T_{\text {chill, }, \text { sut }}\right)$

\section{4 冷媒の物質収支}

蒸発器における単位時間忍たりの蒸発量は吸着器にお ける吸着量に等しいという仮定から椧媒の物質収支は次 式で表される。

$$
\frac{d W_{e \mathrm{u}}}{d t}=-W_{s}\left(\frac{d q_{d e_{e s-c}}}{d t}+\frac{d q_{\mathrm{e}-u d s}}{d t}\right)
$$


3.5 性能評洒パラメータ

システムの性能評価に用いたパラメータを以下に示寸

COPは1サイクル中にシステムに供給した熱量とシステ ムより得られた椧熱量の比であり，次式で表される。

$C O P=\frac{\dot{m}_{c \text { chill }} C_{w^{\prime}} \int_{0}^{t_{\text {cwile }}}\left(T_{\text {chill, in }}-T_{\text {chill,out }}\right) d t}{\dot{m}_{h o t} C_{w^{\prime}} \int_{0}^{t_{\text {wedele }}}\left(T_{\text {hot, in }}-T_{\text {hut out }}\right) d t}$

Cooling Capacity は1 サイクルの平均汾房能力であり, 次 式で表される。

Cooling Capacity $=\dot{m}_{\text {chill }} C_{w} \int_{0}^{t_{\text {.rwtc }}}\left(T_{\text {chill,in }}-T_{\text {chill }, \text { out }}\right) d t / t_{\text {cycle }}$

(9)

なおサイクルシミュレーションに用いた物性值をTab. 2 に示し，基本運転条件を Tab. 3 に示寸

\section{4. シミュレーション結果および考察}

6 ベッド多段型吸着椧凍機に执いて単段・二段力又ケー ド型吸着冾凍サイクルの有効性を検証するため，従来型の 単段型サイクル，二段型サイクルと性能比較在行った。

Fig. 2 に駆動熱源である温水の入口温度を $40^{\circ} \mathrm{C} か 90 \mathrm{C}$ まで変化させて，サイクルシミュレーションを行ったとき のCOPの解析結果を示寸。本サイクルは中〜高温度域に拉 いて COPが高くなって执り、熱源温度が $80^{\circ}$ Cのときに最 も高いCOP を出している. しかし，徉来型のサイクル上比 ベると全温度域において，単段型サイクルと二段型サイク ルの間の值になっていることがうかる。これは単段型と二 段型の結合サイクルの特徽が表れているものと考えられ， COPにおけるメリットはないもの上考える。 しかし, 吸着 冷凍機は未利用であった低温排熱在利用しているため, 本 サイクルではシステムの効率 (COP) 上り出力 (Cooling Capacity)の向上を目的としている.そこでFig. 3 に Cooling Capacity の解析結果を示寸 . 熱源温度 $65^{\circ} \mathrm{C}$ 以上に拀いて徉 来型サイクルより Cooling Capacity が向上して抢り, 熱源 温度が $75^{\circ} \mathrm{C}$ のきには $25 \%$ 向上している. しかし，熱源温 度が $80^{\circ} \mathrm{C}$ のきには $17 \%$ 上向上率が落たている。これは本 サイクルが単段型上二段型の混合サイクルであるため，熱 源温度が低いと単段側の能力が低下し，熱源温度が高いと 二段側の能力が低下するためだと考える。このことから单 段・二段カスケード型サイクルは従来型归イクルに対しる 駆動熱源温度が中温度域のとに最も性能が高い特徵を有 することがわかる。つぎに、Fig. 4 に各サイクルの恰水出口 温度の解析結果を示寸。この結果から汾水を力又夕一ド利 用した場合, 熱源温度 $65^{\circ} \mathrm{C}$ 以上の)上きに従来型サイクルに 比べ出口温度が低くなっている. 泠水出口温度と泠水流量 は密接な関保在持っており，流量在増加させると出口温度 は上昇し, COPと Cooling Capacity は向上寸万。.上って, 需 要側の要求を考慮し, 境界条件として各サイクルの出口温 度を一定としたときに，さらに広い範围の熱源温度に执 て本サイクルの有效性が生じこくると予想される。

\section{5. 結言}

本研究ではシリカゲルー水系におおる単段・二段カスケー ド型サイクルを対象とし，サイクルシミュレーションを行 いCOP, Cooling Capacityを計算した。そして, 従来型の+ イクル上の比較を行い，以下の知見を得た。

（1）冷房能力においては駆動熱源温度が中温度域のときに 従来型サイクルに対し，最も有効性が高い。

(2) COPはいかなる熱源温度に対しても単段型サイクル と二段型サイルクの間の值になる.

今後は実機を用いて本サイクルの性能を実測するる予定であ 万.

Tab. 2 Physical property values.

\begin{tabular}{|c|c|c|}
\hline Symbol & Value & Unit \\
\hline$A_{b}$ & 1.93 & $\mathrm{~m}^{2}$ \\
\hline$A_{i}$ & 0.998 & $m^{2}$ \\
\hline $\mathrm{A}_{\mathrm{c}}$ & 0.665 & $\mathrm{~m}^{2}$ \\
\hline $\mathrm{W}_{\mathrm{cH} H \mathrm{x}}$ & 6.4 & $\mathrm{~kg}$ \\
\hline$W_{\text {clllix }}$ & 4.8 & $\mathrm{~kg}$ \\
\hline$W_{\mathrm{kIII}: \mathrm{X}}$ & 12.67 & $\mathrm{~kg}$ \\
\hline$W_{\text {thitX }}$ & 5.33 & $\mathrm{~kg}$ \\
\hline $\mathrm{W}_{\mathrm{s}}$ & 14.0 & $\mathrm{~kg}$ \\
\hline $\mathrm{U}_{\mathrm{ads}}$ & 1540 & $\mathrm{~W} / \mathrm{m}^{2} \cdot \mathrm{K}$ \\
\hline$U_{\mathrm{des}}$ & 1380 & $\mathrm{~W} / \mathrm{m}^{2} \cdot \mathrm{K}$ \\
\hline $\mathrm{U}_{\mathrm{c}}$ & 4070 & $\mathrm{~W} / \mathrm{m}^{2} \cdot \mathrm{K}$ \\
\hline$U_{c}$ & 3550 & $\mathrm{~W} / \mathrm{m}^{2} \cdot \mathrm{K}$ \\
\hline$R_{p}$ & $0.35 \times 10^{-3}$ & $\mathrm{~m}$ \\
\hline$R_{\text {gas }}$ & $4.62 \times 10^{-2}$ & $\mathrm{~J} / \mathrm{kg} \cdot \mathrm{K}$ \\
\hline $\mathrm{E}_{\mathrm{a}}$ & $2.33 \times 10^{6}$ & $\mathrm{~J} / \mathrm{kg}$ \\
\hline$D_{s o}$ & $2.54 \times 10^{-4}$ & $\mathrm{~m}^{2} / \mathrm{s}$ \\
\hline$Q_{\mathrm{sl}}$ & $2.80 \times 10^{6}$ & $\mathrm{~J} / \mathrm{kg}$ \\
\hline$C_{s}$ & 924 & $\mathrm{~J} / \mathrm{kg} \cdot \mathrm{K}$ \\
\hline $\mathrm{C}_{\mathrm{u}}$ & 4180 & $\mathrm{~J} / \mathrm{kg} \cdot \mathrm{K}$ \\
\hline$C_{v}$ & 4190 & $\mathrm{~J} / \mathrm{kg} \cdot \mathrm{K}$ \\
\hline $\mathrm{C}_{\mathrm{cu}}$ & 386 & $\mathrm{~J} / \mathrm{kg} \cdot \mathrm{K}$ \\
\hline $\mathrm{C}_{\mathrm{al}}$ & 905 & $\mathrm{~J} / \mathrm{kg} \cdot \mathrm{K}$ \\
\hline $\mathrm{L}$ & $2.50 \times 10^{6}$ & $\mathrm{~J} / \mathrm{kg}$ \\
\hline
\end{tabular}

Tab. 3 Base run parameters in the present analysis.

\begin{tabular}{ccc}
\hline Symbol & Value & Unit \\
\hline $\mathrm{T}_{\text {lhot.in }}$ & 80 & ${ }^{\circ} \mathrm{C}$ \\
\hline $\mathrm{T}_{\text {cool, in }}$ & 30 & $\mathrm{C}$ \\
\hline $\mathrm{T}_{\text {chill,in }}$ & 14 & $\mathrm{C}$ \\
\hline$* * \dot{m}_{\text {hot }}$ & 0.8 & $\mathrm{~kg} / \mathrm{s}$ \\
\hline$* * \dot{m}_{\text {cool }}$ & 0.8 & $\mathrm{~kg} / \mathrm{s}$ \\
\hline$\dot{m}_{\text {con }}$ & 0.34 & $\mathrm{~kg} / \mathrm{s}$ \\
\hline$\dot{m}_{\text {chill }}$ & 0.11 & $\mathrm{~kg} / \mathrm{s}$ \\
\hline $\mathrm{W}_{\text {ew }}$ & 25 & $\mathrm{~kg}$ \\
\hline $\mathrm{W}_{\text {conw }}$ & 5 & $\mathrm{~kg}$ \\
\hline$* *$ total & &
\end{tabular}




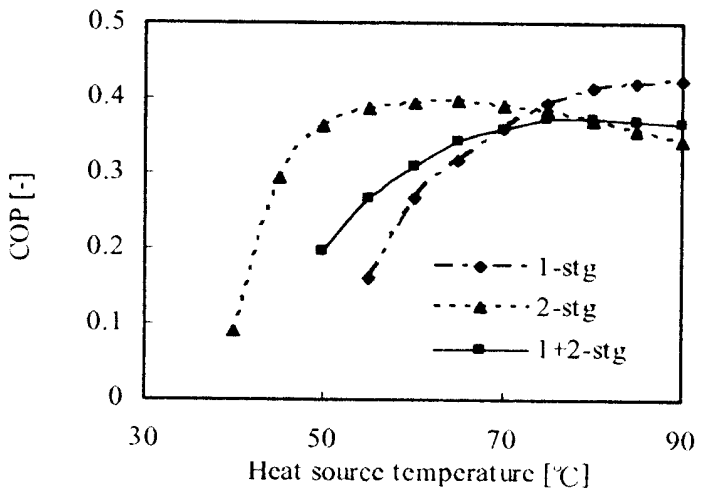

Fig. 3 Effect of heat source temperature on COP of multi-stage chillers.

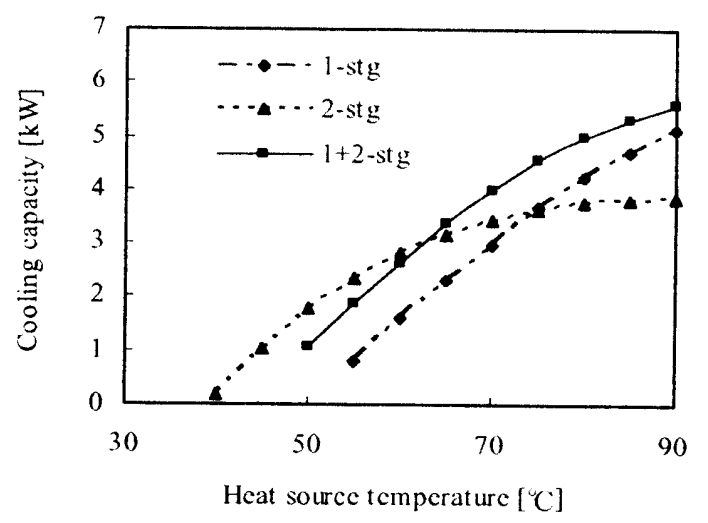

Fig. 4 Effect of heat source temperature on Cooling Capacity of multi-stage chillers.

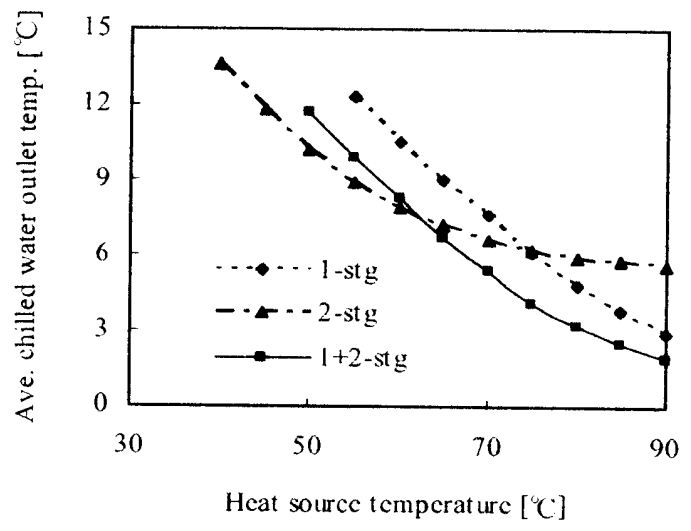

Fig. 5 Effect of heat source temperature on Average chilled water outlet temperature.

\section{参考文献}

(1) Boelman, E. C., Saha, BB., and Kashiwagi, T., (1995) Experimental Investigation of a Silica Gel-Water Adsorption Refrigeration Cycle-the influence of operating conditions on cooling output and COP. ASHRAE Transaction : Research Vol. 101, pp.358-366.

(2) Saha, BB., Alam, KCA., Akisawa, A., Kashiwagi, T., Ng, KC., and Chua, HT., (2000) Two-Stage Non-Regenerative Silica Gel Adsorption Refrigeration Cycle. Proc. of the 2000 ASME Advanced Energy Systems Division, Orlando, USA, Vol.40, pp.65-69.

(3) Saha, BB., Boelman, EC., and Kashiwagi, T., (1995) Computer Simulation of a Silica Gel-Water Adsorption Refrigeration Cycle - The Influence of Operating Conditions on Cooling Output and COP. ASHRAE Transaction: Research Vol. 101, pp.384-355.

(4) Alam, KCA., Saha, BB, Kang, YT., Akisawa, A., and Kashiwagi, T., (2000) "Heat Exchanger Design Effect on the System Performance of Silica Gel Adsorption Refrigeration Systems.", International Journal of Heat and Mass Transfer, Vol.43, No.24, pp.4419-4431.

(5) Alam, KCA., Saha, BB., Akisawa, A., and Kashiwagi, T., (2000) "A Novel Parametric Analysis of a Conventional Silica-Gel Water Adsorption Chiller", JSRAE Transaction, Vol.17, No.3, pp.323.

\section{記号}

\begin{tabular}{|c|c|}
\hline A：伝熱面積 $\left[\mathrm{m}^{2}\right]$ & $\mathrm{C}:$ 比熱 $[\mathrm{kJ} / \mathrm{kg} \cdot \mathrm{K}]$ \\
\hline $\mathrm{D}_{\mathrm{so}}$ : 表面拉散係数 $\left[\mathrm{m}^{2} / \mathrm{s}\right]$ & $\mathrm{E}_{\mathrm{a}}$ : 活性化エネルギー $[\mathrm{J} / \mathrm{kg}]$ \\
\hline m：質量流量 $[\mathrm{kg} / \mathrm{s}]$ & $\mathrm{K}$ : 熱伝達率 $\left[\mathrm{W} / \mathrm{m}^{2} \cdot \mathrm{K}\right]$ \\
\hline L: 蒸発潜熱 $[\mathrm{J} / \mathrm{kg}]$ & Ps : 平衡圧力 $[\mathrm{Pa}]$ \\
\hline $\mathrm{Q}_{\mathrm{st}}$ : 吸着熱 [J/kg] & $\mathrm{R}_{\mathrm{gas}}$ : ガス定数 $[\mathrm{J} / \mathrm{kg} \cdot \mathrm{K}]$ \\
\hline $\mathrm{R}_{\mathrm{p}}$ : 吸着諭平均粒子半径 $[\mathrm{m}]$ & W：質量 [kg] \\
\hline
\end{tabular}

\section{添字}

$\mathrm{cw}$ : 泠却水

c : 凝縮器

ads：吸着工程

HEX : 熱交換器

in : 入口

s：吸着戍 (シリカゲル)

$v$ : 吸着質 (水蒸気) chill : 冷水

e : 蒸発器 des：脱着工程 $\mathrm{b}$ : 吸脱着器 out : 出口 w：吸着質（水） hot：温水 